\title{
Assentamentos rurais e geração de renda: posição social restringida, recursos socioculturais e mercados ${ }^{1}$ \\ Marcos Botton Piccin ${ }^{2}$
}

\section{Resumo}

Neste artigo, analisa-se a posição social dos agricultores de assentamentos rurais na estrutura de poderes econômicos da sociedade brasileira e as perspectivas de geração de renda em um contexto de mercados oligopolizados. Argumenta-se que, enquanto proprietários de pequenos patrimônios produtivos, estão condicionados a um espaço social de integração que tende a determinar uma reprodução simples das condições de trabalho dos integrantes da família. Esse contexto indica algumas opções para o lançamento de alternativas de geração de renda, restringidas às características onde os assentamentos se localizam e às propriedades socioculturais incorporadas diferentemente pelos assentados durante suas trajetórias sociais. As situações analisadas procuraram identificar não só as relações de poder, mas também suas materializações nos sistemas simbólicos resultantes da histórica e estrutural desigualdade da sociedade brasileira. A incorporação de estruturas objetivas e subjetivas pelos agricultores-assentados, expressada nos assentamentos, constitui margem para acessar e construir diferentemente os mercados.

Palavras-chave: Assentamentos rurais; MST; Construção de mercados; Pequenos patrimônios produtivos.

\section{Abstract \\ Rural settlements and income generation: restricted social status, socio-cultural resources and markets}

This paper analyses farmers' social status in rural settlements concerning the structure of economic power in Brazilian society and the perspectives of income generation in the context of oligopolized markets. It is argued that, as owners of small productive assets, they are integrated into a social space that tends to establish a simple reproduction of family members working conditions. This context presents some options for implementation of alternatives to income generation that are restricted to the characteristics of the areas where settlements are located and the socio-cultural properties incorporated by the farmers through their social trajectory. The situations discussed in this paper aim to identify not only power relationships, but also their materialization in symbolic systems stemming from historical and structural inequality in Brazilian society. The incorporation of objective and subjective structures by the settlers, expressed in the settlements, constitutes parameters to access and build markets in a different way.

Keywords: Rural settlements; MST; Market building; Small productive assets.

JEL R230, Q550.

(1) Trabalho recebido em 25 de março de 2009 e aprovado em 10 de dezembro de 2010.

(2) Doutorando em Ciências Sociais no Instituto de Filosofia e Ciências Humanas da Universidade Estadual de Campinas (IFCH/Unicamp) / Bolsista CNPq (Conselho Nacional de Desenvolvimento Científico e Tecnológico), Campinas, SP, Brasil. E-mail: marcospiccin@yahoo.com.br. 


\section{Introdução}

Este artigo analisa a posição social dos agricultores de assentamentos rurais na estrutura de poderes econômicos da sociedade brasileira e as perspectivas de geração de renda em um contexto de mercados oligopolizados. Aborda-se que tal posição confere um espaço social econômico e cultural restringido, em que as distinções socioeconômicas entre agricultores-assentados tendem a corresponder aos diferentes recursos culturais incorporados ao longo de suas trajetórias. Tal análise é realizada a partir da identificação de um campo de autonomia relativa à inserção do agricultor-assentado na estrutura de poderes da sociedade. As objetivações culturais se expressam nas estratégias de reprodução social e fontes de renda monetária e não monetária dos grupos domésticos. Procura-se desvendar como a cultura, entendida como um conjunto de recursos ideais que atuam como disposições sociais e estabelecem uma determinada visão de mundo, orientando formas de pensar, agir e desejar, a partir de uma dimensão sócio-histórica incorporada aos indivíduos, pode se estabelecer no sentido de potencializar e diversificar as fontes de obtenção de renda monetária. Este estudo foi realizado no assentamento Ceres, com 106 famílias, formado, em 1997, no município de Jóia/Rio Grande do Sul (RS), caracterizado pelo cultivo da soja (Gubert; Basso, 2005). No contexto do assentamento, o processo de mercantilização e diversificação da produção por alguns agricultores-assentados tende a ampliar as diferenças socioculturais e econômicas entre os indivíduos.

A bibliografia especializada sobre os assentamentos rurais tem destacado três ângulos de análise que se comunicam: a) a territorialização desses processos sociais que, embora não representem uma desconcentração da posse da terra no país quando analisados em conjunto, modificam significativamente a estrutura agrária das regiões que os recebem, formando as chamadas manchas de assentamentos no território nacional ${ }^{3}$; b) as alterações, geralmente positivas, das condições de vida das famílias e indivíduos, e as relações sociais mantidas interna e externamente aos assentamentos, sejam relacionadas à produção e cooperação, sejam relacionadas às sociabilidades, envolvendo temáticas como gênero $\mathrm{e}$ juventude $^{4}$ e c) as vivências e (re)significações de eventos sociais cotidianos e inusitados em relação aos parâmetros de compreensão desses indivíduos quando na fase da luta pela terra, que podem redefinir padrões de comportamento e esquemas de avaliação socioculturais ${ }^{5}$.

(3) Vide FAO/PNUD - MAARA (1992); Medeiros et al. (1994); Fernandes (1996); Leite (2004); Medeiros e Sosa Junior (2006); Bergamasco e Norder (2003, 2006); entre outros.

(4) Vide Bavaresco (1998); Neves (1999); Leite (2003); Castro (2005); Ferrante e Barone (2006); Piccin e Moreira (2006); Piccin (2009); entre outros.

(5) Vide Gaiger (1994, 1995, 1999); Loera (2004); Gonçalves (2005); entre outros. 
Desse modo, por um lado, as análises se concentram em avaliações socioeconômicas a partir de indicadores estabelecidos previamente pelo pesquisador e, por outro lado, nas significações e representações sociais dos agricultores no que se refere às suas vivências em tais processos. Mas ambos os pressupostos de análise não abordam como esses trabalhadores acionam as distintas lógicas socioculturais incorporadas a partir de suas trajetórias na montagem das estratégias de reprodução social e diversificação das fontes de renda monetária e não monetária. Essa inter-relação e a construção de um campo de autonomia relativa dos agricultores-assentados constituem os objetivos perseguidos neste artigo.

Em uma conjuntura em que há concorrência no setor agrícola, especialmente no caso da produção de commodities, resultando na diminuição do preço desses produtos (Benetti, 2000), as variadas formas da diversidade da agricultura familiar (Schneider, 2006) são pressionadas a reforçar ou a lançar mão de outras estratégias produtivas como maneira de complementar a renda, a exemplo do turismo, mercados de nicho, diversificação produtiva etc. Contudo, nem todas as agriculturas familiares estão em condições de desenvolver, com sucesso, tais alternativas. Dependem, entre outros, da quantidade prévia de capital econômico e terra, dinâmica do grupo doméstico (idade, número, sexo) e condições culturais em que os agricultores se forjaram e expressam por meio de suas atividades. Investigar como esses processos se desenrolam em assentamentos rurais é importante, principalmente, por dois motivos: a) as áreas reformadas no país tendem a constituir as chamadas manchas de assentamentos, que passam a influenciar decisivamente as dinâmicas econômicas dessas regiões devido à criação de novos circuitos mercantis e a demandar um conjunto de bens, além de iniciativas de industrialização e cooperação; b) os beneficiários das políticas de assentamentos tendem a constituir uma parcela da população que vive em condições de subcidadania (Souza, 2003), ou seja, circunstância que não é apenas definida pelas restrições de geração de renda, mas por trajetórias sociais marcadas pela instabilidade das condições de vida. Instabilidades que constituem subjetividades e nas quais podem estar ausentes disposições culturais hegemônicas na sociedade em que os princípios da lucratividade e competitividade são elementos constituintes ${ }^{6}$. As condições culturais produzidas sócio-historicamente podem configurar, portanto, novas racionalidades econômicas e dinâmicas de reprodução social. No Rio Grande do Sul, os assentamentos são em número expressivo, com 312 projetos, totalizando 12.457 famílias (INCRA, 2008). A história de ocupação e migração interna no estado determinou uma dinâmica análoga à formação dos sem-terra (Gaiger, 1994; Zarth, 2006), o que permite

(6) Nesse sentido, vide Piccin (2007, cap. IV). Em outro contexto analítico, vide a abordagem de Moreira (2007, p. 57-67) sobre a ideologia de subsistência. 
afirmar que existe uma diversidade cultural semelhante nos assentamentos do estado. Esta constatação autoriza sugerir que algumas conclusões desse trabalho têm potencial de se estender aos demais assentamentos, pelo menos nesse estado.

O artigo está dividido em três seções, além desta introdução e considerações finais. A primeira seção situa os agricultores-assentados em relação à sua posição nas relações econômicas e sociais e tece considerações sobre a dinâmica de trabalho nos grupos familiares, procurando identificar os campos de suas autonomias relativas. Analisam-se, também, as diferentes estratégias produtivas desenvolvidas pelos agricultores-assentados e fontes de rendimentos. Na segunda seção, investigam-se as trajetórias sociais de dois agricultoresassentados que percebem diferentemente as carências e necessidades sociais, formadas numa dimensão sócio-histórica em processos de socialização e individuação. Nessa direção, analisam-se como, em períodos reconhecidos como de ameaça à reprodução social (devido à diminuição do preço da soja), alternativas produtivas de obtenção monetária são acionadas, além de apresentar os rendimentos auferidos.

A metodologia utilizada valeu-se tanto de técnicas para a geração de dados quantitativos quanto qualitativos: a) um questionário tipo survey, em que foram estabelecidos três sistemas produtivos - sistema produtivo soja, sistema produtivo soja-leite e sistema produtivo diversificado - agrupando, respectivamente, 47, 42 e 17 grupos familiares; b) entrevistas em profundidade com uma amostra de três grupos familiares por sistema produtivo cujo número foi definido pelos critérios de espacialidade e saturação - procurou-se explorar a trajetória social, conhecimentos e saberes no período anterior e durante o acampamento/ assentamento, o que proporcionou uma compreensão de longo prazo sobre a história de reprodução social dos grupos domésticos, tornando os dados gerados pelo questionário tipo survey analisáveis dentro de uma sócio-historicidade; c) vivência do cotidiano dos grupos familiares, em especial dos componentes da amostra, gerando um caderno de anotações de campo. A pesquisa foi realizada entre os meses de maio e julho de 2006.

\section{Agricultores-assentados e o campo de autonomia relativa}

Dois aspectos são fundamentais para situar o campo de autonomia relativa dos agricultores-assentados: a) como a propriedade familiar se articula com o modo de produção capitalista e b) as características internas do grupo doméstico relacionadas com o trabalho e recursos socioculturais ${ }^{7}$. Tais aspectos remetem a um espaço de integração social em suas dimensões política, cultural e econômica

(7) É extensa a bibliografia que trata da dinâmica de funcionamento interno das unidades familiares de produção agrícola, a começar por Chayanov. Neste artigo, realizam-se, na sequência do texto, algumas considerações de tais relações a partir das dinâmicas encontradas no assentamento Ceres. 
em que os agricultores-assentados interagem e acionam as mais variadas estratégias de reprodução social. Além disso, nesse espaço social, construído sócio-historicamente, podem dedicar uma quantidade de trabalho maior ou menor em atividades produtivas, embora as carências dos grupos domésticos possam não ser as mesmas, qualitativa e quantitativamente, assim como os sentimentos de privação, que também podem ser diferentes.

A forma de a agricultura familiar se integrar às sociedades com mercados cada vez mais internacionalizados se alterou, tendencialmente, nos últimos 30 anos. Se o processo de modernização produtivista da agricultura restringiu uma determinada caracterização ${ }^{8}$ do rural, os problemas ambientais, econômicos, sociais e as críticas a tal processo gestam (ram) outras representações desse espaço, redefinindo funções e valores constituidores de novas ruralidades (Wanderley, 2000; Moreira, 2003). Esse contexto criou alternativas de obtenção de rendimentos para os agricultores que permaneceram no campo, e as políticas de desenvolvimento rural passaram a valorizar, como bens de troca, a diversidade da paisagem, das culturas e das tradições (Fonte, 2000). Assim, as novas ruralidades passaram a ser entendidas como um processo dinâmico de constante reestruturação dos elementos da cultura, com base na incorporação de novos valores, hábitos e técnicas, em duplo sentido, tanto em relação ao local quanto em sua inserção na cultura urbana (Carneiro, 1998). Processos de diversificação das estratégias de reprodução social e obtenção de rendimentos também estão sendo acionados pelos agricultores-assentados, como destacado por Leite (2003), Alentejano (2003), Norder (2006), Batista et al. (2008) etc.

Outras duas tendências contraditórias caracterizam esse período: a concorrência em mercados ligados às commodities agrícolas passou a exigir maior escala de produção para a retenção das variáveis econômicas da renda da terra e do lucro capitalista e, por outro lado, houve uma estabilização, e até expansão, do número de unidades agrícolas familiares, como demonstrado por Ploeg (2006) no caso europeu. Esse é um "paradoxo" identificado, mas insuficientemente explicado por Ploeg. De modo geral, tal tendência é tomada de forma positivada pelo autor. Disso resulta uma idealização do que o autor chama de construção da "autonomia" e "emancipação" camponesa, em seu modelo do "modo de produção camponês" (Ploeg, 2006, p. 22-28). Os pressupostos da análise aqui utilizados ${ }^{9}$ podem lançar luz sobre essas tendências contraditórias de modo a destacar tanto as

(8) Associado à ampla autonomia frente à sociedade englobante, sociedade de interconhecimento, entendida a partir da referência à "cidade" por dualidades como atrasado e moderno, incivilizado e civilizado etc. Vide Wanderley (2000).

(9) Embora já citados, vale apena assinalar: a) a forma de articulação com o modo de produção capitalista; (b) as possibilidades de associação e de diversificação de estratégias de reprodução social que, no período considerado, surgiram em uma economia incapaz de absorver maiores contingentes populacionais em trabalhos urbanos e (c) a dinâmica de trabalho interno das unidades familiares. 
oportunidades de obtenção de renda e de construção de mercados nesta nova conjuntura quanto os limites do desenvolvimento econômico e social do conjunto da categoria dos chamados agricultores-familiares. Como se argumentará, dada a emergência das novas ruralidades, as disposições culturais dos agricultores tendem a assumir um papel central no acionamento e potencialização de outras fontes de obtenção monetária.

Para a construção de um campo de autonomia relativa das formas de agricultura familiar no contexto da sociabilidade mercantil é importante a distinção que Moreira (1999a e 1999b) realiza entre espaço social de integração e formas sociais de integração. O autor assinala a posição do agricultor familiar como proprietário de pequeno patrimônio produtivo - meios de produção, entre eles a terra - no âmbito das assimetrias de poderes relacionadas com a concentração de capital, seja em dinheiro, indústrias ou terra. Reconhece-os como subordinados aos desdobramentos da ordem competitiva dominante não apenas na esfera da produção, mas também da circulação de mercadorias, sugerindo, ainda, com a noção de espaço social, a subordinação às dimensões políticas e culturais da sociedade abrangente. Na concorrência intercapitalista, para a fixação do lucro e da renda da terra, há a tendência de que pequenos patrimônios produtivos não realizem tais grandezas econômicas, nas quais o valor retido corresponderia à reprodução simples das condições de trabalho dos integrantes da família e meios de produção ${ }^{10}$. Essas condições levam à perda, por parte dos proprietários desses patrimônios, das características de capitalista, passando a ser um trabalhador que, para exercer seu trabalho, deve ter como requisito a propriedade dos meios de produção ${ }^{11}$. Há, portanto, um campo de força que os "empurra" para outras atividades nas quais esses processos de concorrência são menos intensos. As respostas dos pequenos agricultores vão variar no tempo e no espaço e podem conformar novas formas sociais de integração à dinâmica econômica, seja na agroindústria e agribusiness ou como agricultor em tempo parcial, pluriatividade, dupla vinculação rural e urbana etc. Esse é um dos âmbitos da autonomia relativa

(10) O não reconhecimento dessa posição estrutural em um contexto histórico de generalização da produção de mercadorias implica em equívocos sobre a especificidade da produção familiar. A suposta igualdade entre capitais produtivos ignora não só as especificidades originárias da formação social capitalista, como no caso da profunda desigualdade brasileira na distribuição de ativos, mas os processos de concentração e centralização da dinâmica capitalista (Moreira, 1999a).

(11) Essa não é uma especificidade apenas dos agricultores familiares, mas, de forma crescente, de indivíduos localizados em setores informais da economia, ou ligados a terceirizações e contratos de serviços, em que um patrimônio produtivo prévio é condição de entrada em tais mercados - como trabalhadores por conta própria - (Moreira, 1999b) e que, no limite, podem ter as habilidades incorporadas e reconhecidas nos próprios indivíduos, ou seja, o indivíduo é seu próprio capital, a exemplo da teoria do capital humano, difundida pela chamada Escola de Chicago. Sobre isso, vide a brilhante aula de Foucault (2008), na qual, em 1979, apontava o nascimento da biopolítica. 
desses agricultores, de gestão da força de trabalho de sua unidade doméstica e de necessidades materiais e simbólicas.

A especificidade da 'unidade de produção familiar' e sua articulação com a ordem competitiva para a fixação do lucro e renda da terra podem ser mais bem demonstradas quando se analisam as relações sociais mantidas tanto na produção quanto na circulação de mercadorias. Isso é importante, pois são elementos que compõem o campo de autonomia relativa do setor da agricultura familiar. Além disso, é por meio da análise de tais relações que se pode entender porque, em mercados oligopolizados, ocorre tal "paradoxo", citado anteriormente, no qual, por um lado, empresas agrícolas capitalistas podem "quebrar" e, por outro lado, há a manutenção e até expansão do número de propriedades familiares (Ploeg, 2006).

Na produção, cabe a comparação, para fins didáticos, do processo de trabalho entre uma 'unidade de produção capitalista' e uma 'unidade de produção familiar mercantil'. Para efeito de análise, a geração do valor e o processo de trabalho para a produção de uma mercadoria $M$, podem ser representados, em ambos os casos, por $D-M-D^{\prime}$, sendo $D$ e $D^{\prime}$ valores monetários iniciais e finais do processo produtivo mercantil. Onde $D^{\prime}$ '(final), obtido com a realização (venda) da mercadoria $M$, corresponde à quantia $D$ (investida inicialmente) $+d$, onde $d$ é um determinado valor líquido a mais, porém com significados diferenciados para o caso da unidade de produção capitalista ou familiar. A questão central está em entender como ocorre a formação desse valor a mais $d$, assim como sua fixação, em ambos os casos (Marx, 1983, cap. III e IV; Garcia Jr., 1983, p. 106) ${ }^{12}$.

No caso da 'unidade de produção capitalista', esse $d$ só pode ser gerado se houver uma mercadoria que, durante o processo produtivo, possa gerar mais valor do que contém. Essa mercadoria é a força de trabalho, pois é comprada pelo valor dos produtos necessários à sua reprodução, mas seu uso pelo comprador, ou seja, o trabalho a ser efetivamente realizado, pode gerar mais valor do que aquele pelo qual foi comprado. A geração desse novo valor é feita no processo de produção, onde o trabalho se transforma em uma atividade concreta e socialmente útil (material ou imaterial), possibilitando a reprodução e o aumento do valor inicialmente investido (com instrumentos, objetos e força de trabalho). Assim, a venda da mercadoria $M$ reproduz o valor do dinheiro inicial $D$, ou seja, o valor dos instrumentos, objetos e a força de trabalho, e mais um novo valor porque o valor adicionado pela força de trabalho é superior ao seu próprio valor como mercadoria, que Marx chamou de mais-valia.

(12) Em Marx, a expressão formal D - M - D' representa o movimento do capital, o investimento consciente de $D$ por parte do capitalista para a obtenção de lucro. Contudo, neste artigo, não se "transfere" tal entendimento para o caso do agricultor familiar, pois se entende que o agricultor familiar segue uma linha de raciocínio diferente da do capitalista estrito senso, representado naquela expressão formal. As devidas diferenças e suas justificativas são apresentadas no decorrer do texto. 
$\mathrm{Na}$ 'unidade de produção familiar', a diferença fundamental do processo de trabalho repousa no fato de que o montante do trabalho é dado pelo potencial da família - ou com a ajuda (que assume diversas modalidades) de vizinhos -, mas não é obtido, majoritariamente, por troca mercantil. Temos, assim, que as formas de agricultura familiar se caracterizam pela produção de bens que visam à reprodução da força de trabalho familiar e de suas condições de produção. Casos de maior ou menor especialização produtiva não mudam a conceitualização, mas exigem maior esforço analítico para interpretar a diferenciação do setor da agricultura familiar. No caso de maior especialização, apesar do objetivo não ser mais a produção de valores de uso com o trabalho próprio, mas, sim, a obtenção de valores de uso com o trabalho próprio via mercados, a finalidade primeira de reprodução de suas condições de produção continua a mesma, como, aliás, a de qualquer trabalhador. A circulação simples de mercadorias - a venda para a compra - serve como meio para um objetivo final: a apropriação de valores de uso, a satisfação de necessidades. Na 'unidade de produção capitalista' a circulação do dinheiro como capital é, ao contrário, uma finalidade em si mesma; o valor de uso nunca é tratado como meta imediata do capital, apenas a busca incessante das margens médias de lucro (Marx, 1983, p. 125; Moreira, 1999c) ${ }^{13}$.

Disso resulta que o acesso ao montante de trabalho por laços de parentesco ou por compra via mercantil provoca usos e significados diferenciados desse valor a mais que é produzido: $d$. Na compra via mercantil, $d$ é valor monetariamente apropriado, utilizado para consumo próprio e da família do capitalista, e na ampliação do processo de reprodução de seu capital, ou seja, para o acúmulo de ainda mais valor: na compra de novos instrumentos e objetos de trabalho, e da força de trabalho, assim como novos bens de produção (nesse caso, bens de capital e terra). Esse é o processo de reprodução ampliada de seu capital, se conseguir realizar, no mercado, o valor (mais-valia) incorporado em $M$. Desse modo, a força de trabalho como um fator de produção não faz parte de $d$, mas de $D$. Isso é o que dá sentido à possibilidade de acumulação capitalista. Contudo, pode ocorrer reprodução simples se, na venda de $M$, não conseguir realizar a mais-valia incorporada no valor total de $M$, repondo apenas as condições sociais de reprodução capitalista: os custos com a força de trabalho, instrumentos e objetos

(13) Alguns autores destacam que em uma propriedade rural há outro componente que é o tempo de crescimento e desenvolvimento das culturas agrícolas/criações que, fundamentalmente, não dependeria do trabalho concreto para se realizar. Esse seria dado pela natureza. A esse respeito, conferir a revisão bibliográfica efetuada por Schneider (2003, cap. I). No entanto, com base em Moreira (1999b; 1999c), pode-se argumentar que o conhecimento do tempo de crescimento e desenvolvimento das culturas agrícolas/criações é socialmente gerado e não dado pela natureza 'em si'; assim, está também incorporado o trabalho, ainda que não somente o do agricultor que realiza o cultivo, mas o trabalho como conhecimento gerado sócio-historicamente, como trabalho social abstrato e que pode ser apropriado privadamente pelos proprietários. O problema da primeira consideração é que se entende o meio ambiente natural biofísico em si como dádiva da natureza e não como resultado do conhecimento e do trabalho social abstrato. 
de trabalho. Nesse sentido, mesmo na reprodução simples há a produção de maisvalia, que o capitalista, no entanto, não consegue reter devido, principalmente, a mecanismos de concorrência com outros capitalistas ${ }^{14}$.

No caso da 'unidade de produção familiar', tanto o processo de trabalho quanto as possibilidades de acumulação do valor a mais produzido são diferenciados: aqui, $d$ é equivalente à reprodução da força de trabalho do grupo familiar e $D$ apenas dos instrumentos e objetos de trabalho. Contudo, os conceitos de reprodução simples e reprodução ampliada devem ser ressignificados para serem usados no caso da 'unidade de produção familiar', pois não há geração de mais-valia no processo de produção, implícita nos conceitos quando referidos à 'unidade de produção capitalista'. Nesse sentido, pode ser dito que a reprodução simples na 'unidade de produção familiar' ocorre quando o produto gerado ou a renda resultante é empregada no consumo e atendimento de necessidades sociais da família $(d)$ e na manutenção e reposição dos instrumentos e objetos de trabalho $\left(D^{\prime}\right)$ de que precisa para materializar o trabalho familiar, no período seguinte, para a reprodução das condições sociais e objetivas de produção. A retenção de trabalho excedente, condição para a reprodução ampliada, é fundamental para a constituição de poupança, que pode resultar em uma melhoria das condições de vida assim como para a definição dos padrões de herança e trajetória de seus integrantes, que pode se dar via reprodução de outras unidades agrícolas familiares.

Cumpre ainda ressaltar que o valor inicial $D$ pode expressar os valores monetários de bens de produção (em especial, bens de capital e terra) já disponíveis aos produtores capitalistas ou familiares. Como visto, no que se refere à unidade capitalista, parte de $D$ deverá viabilizar o acesso à força de trabalho de terceiros. Já, em relação à unidade mercantil familiar, parte de $D$ deverá dar acesso aos meios de vida da família do trabalhador, caracterizando, assim, uma unidade de produção e consumo que pode ainda produzir bens agrícolas para consumo próprio.

Outras duas questões devem ser consideradas: os processos de valorização da terra e as possibilidades de fixação ou não desses valores pelos seus proprietários.

Para além da incorporação de trabalho aplicado diretamente na terra, como na preparação para semeadura, adubação, infraestrutura etc., são suficientemente registradas pela bibliografia outras formas peculiares com que a mercadoria terra se valoriza (Wanderley, 1979; Martins, 1979; Moreira, 1999b; Silva, 2000). Resumindo: 1) pela elevação da demanda social dos produtos do trabalho aplicado na terra, como nos casos de urbanização e industrialização; 2) pela incorporação

(14) Há ainda a questão da obsolescência das tecnologias, que age desvalorizando e valorizando os capitais. Para uma leitura desse processo relacionado à agricultura familiar vide Moreira (1999d).

Economia e Sociedade, Campinas, v. 21, n. 1 (44), p. 115-141, abr. 2012. 
de trabalho social não aplicado diretamente na terra, como a construção de estradas, pontes, cidades etc.; 3) pelo conjunto de conhecimentos socialmente gerados sobre os diferentes usos da terra; 4) pelos processos de desvalorização do capital, em geral, em períodos de diminuição da taxa de lucro no sistema. Moreira (2007) ressignifica esse conjunto de rendas, denominadas, em outras elaborações, Renda da Terra I, II e Financeira, compreendidas como Renda da Natureza, pois são específicas da natureza da mercadoria terra. Essa renda, que é formada socialmente, pode ser apropriada pelo proprietário fundiário. Nesse caso, é paga por toda a sociedade e, abstratamente, pelos capitalistas industriais, o que, ao menos teoricamente, constitui uma contradição entre frações do capital. Para Moreira (1999c), tal contradição seria uma questão fundiária do capitalismo.

O processo de "recampenização" do caso europeu, ou seja, "de pessoas tornando-se camponesas", como destacado por Ploeg (2006, p. 42-47), em um contexto de inviabilidade econômica das unidades de produção capitalistas (por não conseguirem reter a Renda da Natureza e a taxa média de lucro), pode ser visto como a resolução daquela questão fundiária assinalada por Moreira. Já, se a 'unidade de produção familiar' não retiver essas duas grandezas econômicas, não significará que se inviabilize, até porque poderá reter o valor correspondente à reprodução da força de trabalho e à reposição dos instrumentos e objetos de trabalho. Agora, se uma 'unidade de produção capitalista' não as mantiver, tenderá a sucumbir perante a concorrência.

Os setores da agricultura familiar, ao incorporarem à mercadoria um tempo de trabalho maior que o necessário para a reprodução simples das condições de produção e sem reterem o valor correspondente a esse trabalho excedente, que é apropriado no processo de circulação, contribuem para a expansão da mais-valia social e valorização do capital em geral. Nesse sentido, a agricultura familiar supre a sociedade com alimentos e matérias-primas a baixos custos relativos quando comparados aos das formas empresariais, que requerem o lucro e a Renda da Natureza. As novas ruralidades, em gestação no período atual, podem abrir, às unidades familiares, o lançamento de novas estratégias de reprodução social para além do setor de produção agrícola. Mas é possível pensar em um progresso social das diferentes categorias da agricultura familiar a partir dessas novas ruralidades?

Nas condições do assentamento rural pesquisado, um lote de terra de aproximadamente 14 ha é o único patrimônio produtivo de uma família de agricultores-assentados. Essa é sua posição de produtora e competidora no mercado. Se produzir commodities (soja ou leite, por exemplo), concorrendo, portanto, em um mercado oligopolizado, deve-se admitir que a categoria de agricultores-assentados ocupa uma das posições mais frágeis entre os competidores devido à sua pequena escala de produção e pelo quase desprezível tamanho de seu patrimônio produtivo, se comparado com capitalistas produtores 
das mesmas commodities. Sendo a ponta mais fraca dessa estrutura social, é a que mais sofre com pequenas modificações e acirramento das disputas entre os capitalistas pela fixação da renda da terra e lucros, o que significa maior instabilidade das condições materiais e simbólicas de vida, em que os sentimentos de privação podem impulsionar a busca de outras fontes de rendimentos.

A pesquisa realizada no assentamento Ceres classificou os 106 agricultores em três sistemas produtivos: diversificado, soja-leite e soja. A composição e origem da pauta de rendimentos dos núcleos domésticos podem ser visualizadas na Tabela 1. As informações apresentadas permitem comparar as fontes e composições das rendas dos agricultores-assentados em cada sistema produtivo $^{15}$.

Tabela 1

Origem e composição dos rendimentos totais brutos dos grupos domésticos em cada sistema produtivo - ano agrícola 2005/2006

\begin{tabular}{l|c|c|c|c|c|c|c|c|c}
\hline \multirow{2}{*}{$\begin{array}{l}\text { Sistemas } \\
\text { produtivos }\end{array}$} & $\begin{array}{c}\text { Total } \\
\%\end{array}$ & $\begin{array}{c}\text { Humano } \\
\%\end{array}$ & $\begin{array}{c}\text { Animal } \\
\%\end{array}$ & $\begin{array}{c}\text { Agrícola } \\
\%\end{array}$ & $\begin{array}{c}\text { Pecuária } \\
\%\end{array}$ & $\begin{array}{c}\text { Benef.* } \\
\%\end{array}$ & $\begin{array}{c}\text { Arr./alug } \\
\text { máquinas } \\
\text { ou } \\
\text { terra** \% }\end{array}$ & $\begin{array}{c}\text { Trabalho } \\
\text { assalariado } \\
\%\end{array}$ & $\begin{array}{c}\text { Benefícios } \\
\text { sociais } \\
\%\end{array}$ \\
\hline Diversificado & 100 & 10,74 & 10,43 & 14,38 & 31,02 & 30,01 & 0,43 & 0 & 2,95 \\
\hline Soja-leite & 100 & 17,06 & 10,74 & 40,28 & 26,72 & 0,66 & 0 & 0 & 4,5 \\
\hline Soja & 100 & 15,98 & 10,63 & 14,02 & 8,61 & 0 & 25,68 & 14,58 & 10,45 \\
\hline
\end{tabular}

* Receita gerada no beneficiamento dos produtos

** Receita gerada pelo Arrendamento/Aluguel: de máquinas, equipamentos ou terra.

*** Resulta da multiplicação da quantidade produzida pelos preços médios na parcela de produção que foi efetivamente vendida.

Fonte do autor.

A tabela mostra formas sociais de integração diferenciadas. Enquanto os agricultores-assentados do sistema produtivo diversificado possuem, como fontes principais, a venda de leite e produtos beneficiados, os agricultores do sistema produtivo soja-leite possuem a centralidade de suas receitas monetárias obtidas na venda da soja e do leite, e os agricultores-assentados do sistema produtivo soja possuem a centralidade de suas receitas monetárias obtidas do arrendamento de parte da terra do lote, do trabalho assalariado e do cultivo da soja ${ }^{16}$. Se analisarmos

(15) Os dados apresentados na tabela foram obtidos a partir das informações declaradas pelos agricultores-assentados. Os dados relacionados à composição dos rendimentos referem-se à amostra de três agricultores em cada sistema produtivo. Assinala-se que não se trata da análise do que se poderia chamar de 'fluxo de caixa', em que receitas e despesas (ou entradas e saídas) são observadas na economia doméstica.

(16) Não foram consideradas outras possíveis fontes de recursos, como ajudas, doações e contribuições familiares, pequenas comercializações entre agricultores-assentados, assim como não se consideraram os créditos agrícolas recebidos. Um detalhamento das composições monetárias e não monetárias é realizado na próxima seção. 
as configurações produtivas encontradas no assentamento em relação à região onde ele se localiza, veremos que se comprova a afirmação de Sparovek (2005, p. 35) de que, no Brasil, “...a produção nos assentamentos segue a tendência geral da produção predominante nos municípios", não se diferenciando muito dela. De acordo com o estudo empreendido por Silva Neto e Basso (2005, p. 101), a região onde se insere o assentamento possui sistemas produtivos caracterizados por lavouras de soja e milho extensas, uma pecuária extensiva de baixos rendimentos, número de empregados permanentes mais elevados, estrutura fundiária mais concentrada e maior nível de mecanização quando comparada com as demais regiões do RS; portanto, com forte presença da agricultura patronal. A pecuária leiteira, por outro lado, é característica das propriedades familiares.

Frente à dinâmica socioeconômica regional, os agricultores-assentados acionam formas sociais de integração específicas e codefinidas por fatores relacionados com: a) composição do grupo doméstico, como número, sexo, idade e força de trabalho dos integrantes; b) composição natural dos lotes; c) acesso ao crédito; d) conjunto de disposições culturais internalizado a partir de suas origens e trajetórias sociais, como conhecimentos e projetos de futuro. Os pontos a), b) e c) são fatores distribuídos de maneira semelhante entre os agricultores-assentados, ou seja, a pesquisa realizada demonstrou que a diversidade de formas sociais de integração encontradas no assentamento não podem ser explicadas unicamente a partir de tais aspectos ${ }^{17}$. Sustenta-se a hipótese, discutida acima, de que, dadas as condições estruturadas pelo campo de autonomia relativa, as distintas disposições culturais incorporadas pelos agricultores-assentados emergem como centrais na diferenciação socioeconômica no assentamento estudado.

A opção metodológica de analisar a trajetória social de dois agricultoresassentados - um do sistema produtivo diversificado e outro do sistema produtivo soja - permite expor, com maior profundidade, exemplos das margens de manobra que o campo de autonomia relativa configura. Tal opção ganha em detalhes devido aos comportamentos descritos com relação aos agricultores, tendo em vista as conjunturas socioeconômicas enfrentadas no assentamento e o acionamento, ou não, de oportunidades abertas, em algum grau, pelas novas ruralidades. Contudo, na análise das trajetórias sociais, não são apenas as "histórias" individuais que vêm à tona, mas fundamentalmente uma série de posições sucessivamente ocupadas pelo(s) agente(s) em um determinado espaço social. O próprio conjunto de relações objetivas nas quais o(s) agente(s) esteve(estiveram) ligado(s) direta ou indiretamente necessita ser analisado (Bourdieu, 1996). Assim, tanto aspectos da formação do espaço agrário do RS, do ambiente regional e dos poderes aí

(17) A discussão minuciosa de tais aspectos é realizada em Piccin (2007, cap. IV). Vide também Piccin (2011). 
hegemônicos quanto os do próprio assentamento e dos demais agricultoresassentados aparecem na análise dos dois casos.

\section{Trabalho, trajetórias, carências e dispositivos socioculturais}

É com a força de trabalho potencial do grupo familiar que o agricultorassentado fundamentalmente organiza as atividades produtivas em seu lote e procura gerar as condições materiais e simbólicas de atendimento das carências dos integrantes. Internamente à unidade do grupo doméstico pode haver situações que diminuem a presença efetiva de mão de obra, como em casos de criança pequena, velhice ou doença enfrentada por algum membro, e que retiram a identificação de pertencimento à unidade de trabalho familiar. Contudo, essas situações estão longe de impor limites às atividades desenvolvidas pelo agricultor no lote, que pode aumentar a utilização dos trabalhadores disponíveis na unidade familiar e/ou recorrer aos mutirões e ajudas ${ }^{18}$. A mulher participa das atividades consideradas prioritárias para a obtenção de renda monetária em três circunstâncias: ajuda, quando os filhos são pequenos, ou seja, quando há poucos trabalhadores na unidade familiar; quando o grupo familiar passa por períodos considerados difíceis para a produção das condições necessárias à reprodução social e em períodos de pico do ciclo agrícola, que exigem mais trabalho da unidade de produção familiar do que o normalmente despendido. O expediente de mutirões e ajuda de vizinhos geralmente é alçado também em momentos que exigem maior quantidade de trabalho do que o grupo doméstico pode fornecer. Nesses casos, pode haver a "liberação" da mulher dessas atividades.

Quanto aos mutirões, ou quando ocorre um "convite" a alguns vizinhos para que se disponibilizem a ajudar, a presença de algum membro de outros grupos domésticos sempre é esperada pois, caso contrário, o grupo doméstico que não enviou ninguém pode também não receber ajuda quando solicitada. Opera-se, dessa forma, uma modalidade de reciprocidade no trabalho que não é necessariamente realizada entre membros de uma mesma família ligados por laços de parentesco, mas que ocorre entre "iguais" (Woortmann, 1990, p. 29), entre agricultores-assentados.

A ajuda pode ser sempre acionada quando o grupo familiar não consegue realizar todos os trabalhos em época de pico do ciclo agrícola no lote e é assim designada quando os mesmos trabalhos não correspondem aos de outros lotes, aos de outros grupos domésticos, como na dobra do chamado milho safrinha, por não

(18) A referência, na fala dos agricultores-assentados, à ajuda nestas condições procura localizar os trabalhos prioritários do homem e da mulher na propriedade. A presença da mulher "em casa" viabiliza e ajuda o trabalho realizado pelo homem na construção do "projeto de vida no lote". Um projeto que é de ambos, por meio da instituição do casamento, e que se inicia quando a terra é conquistada. Como o homem é o responsável pelas atividades principais, por obter renda monetária, pode solicitar ajuda tanto à mulher quanto aos vizinhos.

Economia e Sociedade, Campinas, v. 21, n. 1 (44), p. 115-141, abr. 2012. 
ser realizada por todos os agricultores-assentados. Contudo, como na safra normal do milho, que ocorre durante os meses de janeiro e fevereiro, se vários agricultores-assentados precisam de ajuda, pode-se desenvolver o chamado mutirão. O mutirão é a reunião dos agricultores-assentados em uma mesma lavoura para "vencer os serviços" de um dado grupo doméstico e, na sequência, a lavoura de outro agricultor-assentado é assistida, assim, sucessivamente, até que todos tenham seus trabalhos realizados. Segundo um dos agricultores-assentados entrevistados, os mutirões ocorriam com maior frequência no início do assentamento, mas com o desenvolvimento da soja por grande parte dos agricultores-assentados essa modalidade de trabalho diminuiu, embora não as ajudas. No entanto, com a frustração da soja devido à diminuição dos preços a partir de meados de 2004 e o endividamento que já atingia vários deles, os mutirões foram novamente acionados para o desenvolvimento de trabalhos comuns aos grupos domésticos, como na colheita do milho. Para Woortmann (1990, p. 29), a troca de trabalho possui um sentido de afirmar a condição moral do pai, haja vista que viabiliza as condições para a reprodução social do grupo doméstico.

Nesse contexto, assalariar trabalhadores para realizar tarefas na propriedade da família pode cumprir um mesmo sentido, o que, no entanto, não garante que o rendimento líquido seja igual, por ter que descontar os custos com o pagamento da mão de obra. No assentamento Ceres, ocorre o assalariamento dos parentes que estão se preparando para se estabelecer nos acampamentos. Contudo, os parentes recebem salário por não possuírem grupos domésticos e lote de terra no assentamento, o que possibilitaria a troca de trabalho. Nesse sentido, assalariar parentes temporariamente também pode ser entendido como uma espécie de ajuda mútua. Ou seja, o agricultor-assentado ajuda o assalariado porque este está ganhando algum dinheiro enquanto espera o acampamento, o que, por sua vez, ajuda o agricultor-assentado a realizar os trabalhos no lote, como argumentou um dos agricultores-assentados visitados pelo autor. Essa situação tende a ser ocasional e transitória, marcada pela excepcionalidade da existência de parentes dispostos a seguir o caminho da luta pela terra e pelas conjunturas de formação dos acampamentos.

Dessa forma, seja utilizando sua unidade doméstica ou lançando mão de outros meios para realizar os trabalhos no lote, depende do agricultor-assentado dimensionar a extensão de quais atividades produtivas deseja realizar e a consequente jornada de trabalho que está disposto a manter. No contexto das assimetrias de poder representadas pela dinâmica produtiva regional e sua inserção em mercados oligopolizados, o trabalho do agricultor-assentado é o único fator que depende apenas e exclusivamente de si próprio para vencer os obstáculos que sua posição social the impõe. Inserido na sociedade como possuidor de pequeno 
patrimônio produtivo, num espaço social restringido e que define uma participação mercantil mutante, como argumentado na primeira parte do artigo, a resultante de seu processo de trabalho tem que garantir a sobrevivência do grupo doméstico e ser suficiente para cobrir as despesas futuras com instrumentos e objetos de trabalho.

As carências de consumo, contudo, podem aumentar ou diminuir, seja por novas necessidades sociais criadas por maior ou menor número de consumidores na família, ou por necessidades culturais diferenciadas entre os grupos familiares por possuírem uma formação sócio-histórica e incorporação de recursos socioculturais diferenciados. Dessa forma, as regras de consumo necessário sofrem variações e não evidenciam, por conseguinte, que todos os agricultoresassentados tenham as mesmas exigências de consumo, por mais que haja níveis de consumo socialmente considerados como mínimos e que aparecem nas falas dos agricultores-assentados. O que é privação para uns pode não ser para outros. O que pode ser considerado o mínimo suportado para uns pode não ser para outros.

O que se está argumentando é observado nas trajetórias dos dois agricultores-assentados analisadas a seguir, seja por meio dos cultivos agrícolas e criações utilizadas preferencialmente para o autoconsumo, quanto para a comercialização. Esses cultivos, além de não serem valorizados da mesma maneira, representam um fator de distinção social entre os agricultores-assentados e de possibilidade de acumulação.

O agricultor-assentado do sistema produtivo diversificado é aqui nomeado Sr. Pedro e o agricultor-assentado do sistema produtivo soja, Sr. Francisco, ambos nomes fictícios.

No primeiro caso, ter a mesa cheia significa fartura, condição para deixar de ser pobre. Se adquirir determinados bens materiais com a venda das culturas agrícolas comerciais e com o leite é identificado como difícil, podendo-se tolerar e até renunciar, por mais que a postura não seja de resignação, a condição para manter a noção de dignidade da família é identificada por uma alimentação considerada abundante e variada. Sinal de pobreza seria se à mesa não estivessem, entre os principais produtos, os oriundos da horta, como a mandioca, carne de aves, suínos ou bovinos, leite, além de batata-doce, arroz, feijão, pão de trigo, derivados de milho, geleias e doces. Obviamente, não são utilizados todos os produtos nas mesmas refeições, destacando-se que a presença constante de pelo menos um tipo de carne depende basicamente das associações que a mulher prepara. Não possuir uma alimentação em fartura é considerado uma resignação à pobreza. Nas palavras do Sr. Pedro, com esposa e um filho com idade de 8 anos:

[...] pobre, pobre a gente não é, não tem tantas coisas assim [...], pode ver, a gente tem pouca coisa [...]. Carro, um trator bom, maquinário, uma casa grande [...], isso 
a gente não tem. Então, rico a gente não é. Mas também não é pobre, nossa mesa sempre foi cheia, sempre teve fartura, ao contrário de outros aqui [no assentamento] que nem horta têm em casa [...].

Há nessa citação um reconhecimento do que é ser rico e do que é ser pobre, embora o informante não se identifique com nenhuma das categorizações que estabelece. Chama atenção que as referências por ele utilizadas para definir o que é ser rico sejam semelhantes às características identificadas nos agricultores granjeiros ${ }^{19}$ próximos do assentamento. Possuir "carro, um trator bom, maquinário, uma casa grande" são elementos da definição de uma condição social na qual ele não se encontra, mas que faz parte de seu cotidiano quando mantém relações, sejam elas de vizinhança ou produtivas, como no caso do aluguel de alguma máquina agrícola com os agricultores granjeiros, mesmo que também possam ser considerados pequenos produtores. É possível que a categorização rico tenha uma significação que procura expressar a aquisição dos elementos necessários para materializar os projetos de vida almejados; neste sentido, os elementos para onde olha e que servem como modelo de referência para guiar suas ações no lote. Por outro lado, também não é pobre. A condição de pobre está relacionada às diferenças identificadas em relação a outros agricultoresassentados. Tirar do resultado de seu trabalho, majoritariamente, os produtos do autoconsumo para se ter uma "mesa sempre cheia", com "fartura" é uma distinção social em relação àqueles "que nem horta têm em casa", identificado como um elemento definidor da condição de ser pobre. Neste sentido, possuir uma alimentação considerada variada e farta passa a ser um valor social, um fator componente da dignidade da família.

No segundo caso, o fato de não possuir uma quantidade de produtos agrícolas e criações destinadas ao autoconsumo como o seu vizinho, Sr. Pedro, não figura entre os padrões de consumo como uma privação definidora de uma condição material inferior. As identificações de padrão mínimo de autoconsumo estão ancoradas em outras referências socioculturais que não valorizam, necessariamente, ter o cultivo e criação desses produtos no lote. No entanto, a capacidade de adquirir parte dos alimentos no supermercado da cidade é um elemento de valorização na família. No grupo familiar do Sr. Francisco, formado por esposa, 3 filhas de até 11 anos e 1 filho de 4 anos, o pão de trigo e até mesmo a carne de galinha não são alimentos produzidos internamente no lote. De modo geral, foi possível perceber que os componentes das dietas alimentares costumam ser arroz, feijão, mandioca, pão de trigo e carnes, essa última não diariamente. A produção de autoconsumo não é valorizada como na família do Sr. Pedro; não constitui, portanto, um componente definidor de um valor social conformador de

(19) Agricultores vizinhos ao assentamento que usam técnicas da agronomia moderna no cultivo das terras, especialmente com a soja, cujas propriedades são chamadas de 'granjas'. 
sentimentos de privação. Da mesma forma, não parece ser um elemento de comparação com relação aos modelos considerados ideais de vida e de projetos de futuro. No entanto, ganha relevo o dimensionamento da jornada de trabalho dedicada às atividades no lote. Aparentemente, torna-se desnecessário manter uma jornada de trabalho maior que aquela já realizada, pois as condições materiais presentes nos lotes não representam para o Sr. Francisco como justificadoras de uma dedicação maior, como a realizada por seu vizinho. Durante a entrevista concedida ao autor, quando os assuntos referentes à formação do assentamento e às diferenças entre os agricultores-assentados foram abordadas em sua fala, declarou que:

[...] dentro do assentamento os assentados trabalham [...]. Eu trabalho, se for comparar com o vizinho aqui da frente, eu não trabalho que nem ele. Mas, olha, se for comparar eu não estou tão atrás dele, não. Eu tenho minhas coisinhas, mesmo não se "matando" de tanto trabalhar. Também não dá para ser escravo do trabalho $[\ldots]$.

É provável que a comparação esteja observando as características semelhantes de moradia, ausência de automóvel e condições aparentes de vestimenta - a posse de um trator pelo Sr. Pedro era vista pelo Sr. Francisco como algo que "mais incomodava do que ajudava", por estar, frequentemente, em conserto. Assim, não havia sentido dedicar uma jornada de trabalho maior se as condições materiais consideradas não o deixavam "tão atrás" do Sr. Pedro, que se "matava de tanto trabalhar". O "excesso" de trabalho realizado por seu vizinho não trazia vantagens materiais consideráveis quando comparado com a sua situação. Neste sentido, desprovido simbolicamente das carências relacionadas com as atividades de autoconsumo, não considerava o trabalho aí despendido como um fator constituinte de uma moralidade para com o grupo doméstico. De forma análoga, certa despreocupação com a melhoria econômica exprime uma ação prioritária pela não autoalimentação do trabalho, ou seja, a possibilidade de utilizar seu tempo com o trabalho até o momento em que o considera desmedido, não comprometendo a possibilidade de dispô-lo como bem entender.

Para se compreender melhor tais significações e as resultantes em termos de estratégias de reprodução social alternativas, alçadas quando ocorre a diminuição do preço da soja, a partir de meados de 2004, é necessário perceber alguns marcadores nas trajetórias sociais de ambos os agricultores-assentados ao longo dos processos de socialização e individuação constituidores de disposições sociais atuantes que orientam suas formas de ver e se ver no mundo. Sem pretender reconstituir em detalhes a história individual de cada um, assinalam-se, a seguir, alguns desses marcadores.

O Sr. Pedro é filho de pequeno agricultor da região do Alto Uruguai, onde a família tinha 11 ha. Como tal, sua família estava inserida num contexto de plena 
modernização, a partir da década de 1960, em uma economia mercantil de trocas desiguais, como proprietária de pequeno patrimônio produtivo. Esse processo consolidou cadeias produtivas que integraram os pequenos agricultores no âmbito da comercialização de commodities e abriu, ao menos ideologicamente, maiores possibilidades de acumulação de capital, subentendidas a partir da ideia de "melhorar de vida". Essa integração que, para os pequenos agricultores, pode ter impulso inicial pelo desejo de realizar princípios morais, ingressa, reforça e constitui uma racionalidade mercantil monetarizada (Woortmann, 1990). É a vivência da posição de filho de pequeno agricultor que permite a reprodução das referências culturais, como aquelas relacionadas com a noção de trabalho, de carências e necessidades sociais, também expressadas no assentamento ${ }^{20}$. Quando vivenciou a forma acampamento (Sigaud, 2000), participou de cursos de produção relacionados com a agroecologia, fez "estágio" em cooperativas de assentamentos rurais que possuíam estratégias comerciais em circuitos locais, como a venda de produtos nas cidades, e foi membro da direção do acampamento. Quando em assentamento, compôs sua estrutura organizativa, assim como uma cooperativa aí formada, o que proporcionou a ampliação de contatos sociais no município de Jóia e região.

Desde o início do assentamento até meados de 2004, quando ocorreu a queda do preço pago à saca da soja, o Sr. Pedro tinha, como principais atividades comerciais, a sojicultura e a bovinocultura leiteira ao lado de uma grande variedade de produtos para o autoconsumo. O cultivo inicial dessas últimas possui impulso em uma referência cultural, uma carência socialmente construída e exteriorizada na ação de sua família no lote. Quando houve queda do preço da soja, a família passou a alçar algumas atividades de autoconsumo com objetivo comercial, criando novos canais de comercialização no município de Jóia e região. Nesse período, as estratégias produtivas no lote foram guiadas pelo desejo de "se estabilizar economicamente e não correr mais o risco de ter apenas uma safra por ano", como no caso da soja. Desse modo, para o casal, "a ideia foi fazer, de forma agroecológica, de tudo um pouco e vender de tudo um pouco". As referências então atualizadas são aquelas vivenciadas durante os cursos de agroecologia no período de acampamento com assessores do MST e em visitas a outras cooperativas. Assim, suas fontes de renda monetária eram o leite, derivados de cana-de-açúcar (que, segundo o agricultor-assentado, "rende em 1 hectare...", o equivalente à 8 hectares de soja), aves, suínos, amendoim, batata-doce, cebola, alho e compotas; o que lhe conferia uma Renda Monetária Líquida anual média

(20) Vide, para as situações de "perda" daquelas referências socioculturais, os casos relatados por Roche (1969) da "acaboclização" de colonos quando em situação miserável de vida. 
(RML) de R\$ 9.034,65 e uma Renda Indireta anual média do Autoconsumo (RIA) (humano e animal) de $\mathrm{R} \$ 4.850,66^{21}$.

O Sr. Francisco, por outro lado, filho de meeiro/empregado temporário em granjas na Região do Planalto, trabalhou nas mesmas condições de seu pai antes de ir para o acampamento. Segundo sua entrevista, os trabalhos desenvolvidos nas granjas eram relativos a pequenas frações de terra, geralmente inadequadas ao uso de máquina, como naquelas onde há a derrubada da mata. Em tal posição social, o indivíduo costuma receber a maior parte das sementes e insumos agrícolas do proprietário da terra para realizar o cultivo em troca de uma parte da colheita a ser paga geralmente em produtos. Cabe ao proprietário as decisões sobre o sistema de cultivo assim como a quantidade e qualidade do produto. Mesmo que venha a ter alguma participação no processo de decisão sobre o que e como plantar, é o proprietário da terra quem dá a palavra final. Cabe ao trabalhador apenas executar o planejamento estabelecido previamente pelo proprietário. Ademais, fica afastado das trocas monetárias relacionadas com a compra de insumos e movimentações bancárias, como os financiamentos agrícolas. A lógica de relacionamento com o trabalho é de sujeição, ao contrário de quando se é proprietário de frações de terra e dali se tira o sustento da família. A inexistência de patrimônio produtivo por parte da família pode ter impedido que se manifestassem os valores do modelo de colono parcelar, relacionados, por exemplo, com a noção de trabalho que valoriza a regularidade, a dedicação e a parcimônia. Com a fronteira agrícola fechada e devido à crescente mecanização das terras, as possibilidades de emprego diminuem assim como a remuneração. Além do mais, em sua entrevista, ganha destaque a percepção de uma espécie de "pai-patrão", pois o dinheiro adquirido por meio do trabalho em granjas era entregue para o "pai administrar", contexto que, possivelmente, tenha formado uma perspectiva de entrar na luta pela terra, orientada, sobretudo, pelo desejo de autonomia sobre os resultados de seus trabalhos. Em acampamento, não participou de cursos relacionados à produção nem teve um envolvimento destacado na militância política, o que também não

(21) Para o cálculo das rendas dos produtos vendidos, foram considerados os preços médios oferecidos ao agricultor. Para o cálculo da renda indireta dos produtos para autoconsumo (humano e animal) foram utilizados os preços médios ao consumidor ao longo do ano (Garcia Jr., 1994, p. 91). Os produtos estocados destinados ao comércio foram considerados vendidos; os produtos estocados destinados ao autoconsumo também foram contabilizados no preço total dos produtos dessa rubrica. Para o cálculo da RML, foram subtraídos, da Renda Monetária Bruta, os custos com insumos para os tratos agrícolas e a criação de animais (fertilizantes, herbicidas, fungicidas, inseticidas, ração, concentrado, sal mineral, medicamentos etc.), manutenção de veículos, máquinas e equipamentos, aluguel de máquinas e equipamentos para semeaduras e tratos culturais, salários eventualmente pagos a trabalhadores e outros custos. Nesse sentido, procurou-se considerar os valores monetários declarados pelos agricultores-assentados efetivamente praticados no custeio ao longo do período considerado nesta pesquisa. Não foram imputados valores relativos ao custo de oportunidade à mão de obra familiar ou à depreciação de máquinas, equipamentos, edificações e animais, tampouco a renda da terra. Os valores citados correspondem à média da amostra dos agricultores-assentados selecionados no sistema produtivo diversificado em um ciclo agrícola referente aos anos 2005/2006

Economia e Sociedade, Campinas, v. 21, n. 1 (44), p. 115-141, abr. 2012. 
ocorreu com relação à participação em instâncias de direção do assentamento e da cooperativa.

Desde o início do assentamento, sua principal atividade produtiva comercial consistiu na sojicultura e/ou arrendamento parcial ou total da área cultivável de seu lote. A atividade leiteira é desenvolvida com fins comerciais nas entressafras da soja, período no qual se desenvolvem, naturalmente, forrageiras sobre a terra. Nos períodos de diminuição do preço da soja, ou por algum outro motivo que queira ter uma renda "extra", assalariam-se trabalhadores temporariamente em grandes cooperativas regionais, como na Agropan ${ }^{22}$, geralmente em épocas de colheita de commodities agrícolas. A RML anual média, nesse caso, era de $\mathrm{R} \$ 3.746,67$ e uma RIA anual média (humano e animal) de $\mathrm{R} \$ 2.371,8$.

No caso do Sr. Francisco, é importante perceber o que significa a "transformação" de meeiro/trabalhador temporário em granjas agrícolas em agricultor-assentado. $\mathrm{O}$ fato de possuir um lote de terra o insere em um ambiente que demanda um conjunto de decisões a serem tomadas relativas às formas de ocupação de tal área. Neste ambiente, os comportamentos sociais esperados dos agricultores-assentados por assessorias, direções do MST e políticas públicas são no sentido de potencialização dos recursos, visando a maximização econômica sobre os lotes de terra. A posição social por ele ocupada na estrutura de relações sociais limitou o desenvolvimento de capacidades nessa direção. Além disso, as referências e padrões culturais constituídos do que seria "melhorar de vida" e "ascender socialmente" estão dados por outros princípios que não apenas o desejo de acúmulo econômico mas, principalmente, de autonomia no trabalho. Realidade social esta, que, no entanto, não é vivida sem tensionamento, uma vez que seu modo de vida e as estratégias de reprodução social são vistos por outros agricultores-assentados, direções do MST e assessoria técnica com certo desprezo. Essa situação é reconhecida quando, em entrevista, afirmou: "acho que eu não sei me administrar". Tal declaração, em um contexto de justificativa para suas opções de estratégias de produção sobre o lote, é o reconhecimento de um conjunto de dificuldades e limites impostos pelos processos de socialização bem como as dúvidas, medos e insegurança em se aventurar em novas formas de organizar a produção.

Mesmo considerando o fato de que o Sr. Francisco menciona as experiências de seu vizinho, a exemplo da venda de produtos antes dedicados ao autoconsumo, como referência para constituir alternativas de renda à soja, isso parece mesclar-se com outros dois sentimentos: de ameaça à autonomia, ao utilizar seu tempo com outras ocupações, tornando-o "escravo do trabalho" e,

(22) Cooperativa Agrícola do Município de Tupaciretã. 
principalmente, de certo "medo" de que essas experiências testadas pelo seu vizinho não dessem certo, ou seja, que não se constituíssem, de fato, em alternativas de renda monetária à soja. Disso resultava seu comportamento reticente.

Com relação às atividades de autoconsumo, é importante observar os comportamentos dos dois agricultores-assentados tendo em vista suas localizações nos sistemas produtivos expostos na Tabela 1. A maior ou menor valorização desses produtos é uma tendência observada, que corresponde a seus pares nos sistemas produtivos desenvolvidos, pois tanto a RML quanto a RIA são médias que correspondem à classificação da Tabela. A Tabela indica uma tendência amplamente conhecida: quanto mais recursos monetários e alimentares dispuser o grupo familiar, menores serão as necessidades de assalariamento de seus integrantes (Garcia Jr., 1994, p. 90), o que é reconhecido tanto nas trajetórias analisadas quanto nas de seus pares em cada sistema produtivo. A quantidade produzida desses alimentos pode orientar também o comportamento dos agricultores-assentados, escolhendo quantidades de produtos para venda ou disponibilizando, no mercado, sua mão de obra para trabalhos agrícolas ou não agrícolas (Guanziroli et al., 2001, p. 23).

De certa forma, esta situação pode ser observada no caso dos dois agricultores-assentados aqui analisados: se antes da diminuição do preço da soja, em 2004, o cultivo dessa leguminosa por ambos os agricultores-assentados assim como as diferenças de jornadas de trabalho não reverteram em diferenças materiais significativas, o mesmo, agora, tende a não ocorrer. A presença e valorização, no lote do Sr. Pedro, de atividades voltadas inicialmente para o autoconsumo constituem-se em alternativas produtivas comerciais, o que, em algum grau, reverte o diferencial de trabalho em maior diferencial de renda, aprofundando as diferenças socioeconômicas entre os agricultores-assentados.

No contexto de uma autonomia relativa definida por mercados oligopolizados (especialmente os da soja e do leite) por seus pequenos patrimônios produtivos e pela valorização de produtos operada pelos processos das novas ruralidades, como a valorização de produtos ecológicos, a formação sociocultural assume um papel importante. Neste sentido, preliminarmente, pode ser sugerido que, de certa forma, a melhoria das condições materiais de vida e a diferenciação social interna ao assentamento residem no aumento da jornada de trabalho e em um sistema de produção que não tenha, em sua centralidade, as culturas produtivas comercializadas como commodities agrícolas. No caso do Sr. Pedro, a existência de um sistema cultural que valoriza moralmente determinadas atividades produtivas e uma relação do tipo ético moral para com o trabalho, sendo fator de dedicação e esforço, proporciona um comportamento que pode permitir lançar mão de outras atividades comercializáveis - seja pela existência de atividades de 
autoconsumo consideradas em abundância, que permite investidas e experiências comerciais, seja pela disponibilidade de intensificação da quantidade de trabalho, seja pelo conhecimento/estabelecimento de contatos realizados quando compunha espaços de direção do assentamento e da cooperativa, que são acionados com objetivos de estabelecer circuitos comerciais locais e regionais. Tais condições configuram apenas uma parte dos agricultores do assentamento pesquisado.

Note-se que, como argumentado por Moreira (1999a), a posição restringida que essas unidades domésticas possuem na estrutura de relações mercantis e na concorrência em mercados imperfeitos (oligopolizados) determina o lucro e a renda da terra próximos a zero. Ou ainda, se a colheita for ruim ou se os preços dos produtos de seu trabalho caírem, a reposição das condições materiais de produção pode ser efetuada às expensas do consumo familiar ou, ainda, ocorrer o fenômeno conhecido como descapitalização. Isso conforma um espaço social mutante de integração desses setores sociais, deslocando os proprietários com menor patrimônio produtivo para outros ramos de produção e outras atividades produtivas desde que tenham recursos socioculturais que permitam essa migração, como aqueles que o Sr. Pedro expressa para realizar a produção e venda de produtos antes destinados ao autoconsumo. Nesse sentido, a utilização mais intensa de instrumentos e objetos de trabalho, assim como a do trabalho da unidade familiar, pode permitir, embora não garanta, um maior controle sobre a reposição das condições sociais e materiais de produção.

Contudo, e as perspectivas de progresso social e econômico para os demais pequenos agricultores que não se encontram nas mesmas condições do $\mathrm{Sr}$. Pedro (considerando que agricultores como ele estejam em vias de consolidação, ou seja, que suas estratégias produtivas permitam uma reprodução ampliada)? Permanecerão de tal forma subordinados aos poderes do mercado que favorecem os grandes produtores de commodities, como o caso do Sr. Vanderlei, em que a opção de arrendamento parcial ou total do lote a granjeiros pode ser vista como a melhor alternativa para a obtenção de renda? As alternativas de nichos de mercado abertas pelos processos das novas ruralidades tendem a ser incapazes de proporcionar progresso econômico e social para o conjunto da categoria dos agricultores familiares se não acompanhadas de fortes políticas públicas de fomento e compra da produção por preços que transfiram renda real a esta parcela da população, considerando as especificidades características da categoria dos agricultores-assentados (como a multiplicidade de trajetórias e recursos socioculturais) frente aos demais agricultores familiares.

\section{Conclusões finais}

Analisar as formas de agricultura familiar no contexto dos campos de autonomia relativa a partir da posição na estrutura de poderes da sociedade, que 
apresentam semelhanças e diferenças no tempo e espaço, é uma tentativa de não supervalorizar nem as autonomias dos agricultores-assentados nem as restrições impostas pelo campo de poderes. Isso não desqualifica as lutas e iniciativas coletivas e individuais na tentativa de alcançar os ideais de vida almejados, mas valoriza e reconhece os diferenciais de poderes associados à distribuição desigual da terra. A não consideração do campo de autonomia relativa pode provocar equívocos na análise e leitura da diversidade da agricultura familiar bem como das possibilidades de desenvolvimento e progresso social. A dificuldade em considerálo tem aparecido em alguns estudos como forma de identificar a agricultura familiar com uma "auréola" de superioridade em relação às empresas capitalistas da agricultura e grandes propriedades, como se algum "espírito camponês" imbuísse esses indivíduos de uma missão histórica. Outro equívoco é desenhar um "belo mundo camponês", que vê de forma romântica a situação dos pequenos proprietários e supervaloriza as iniciativas comerciais alternativas, como se fosse possível sua generalização nas condições de poderes representados pelos mercados

capitalistas. Em tais análises não há a consideração, ou não se dá consequência analítica, à posição social que a agricultura familiar ocupa no contexto de um mundo caracterizado, cada vez mais, por oligopólios, financeirização e pela concentração do capital.

As situações abordadas neste artigo procuraram identificar não só as relações de poder, mas, e principalmente, suas materializações nos sistemas simbólicos resultantes da histórica e estrutural desigualdade da sociedade brasileira. Essas condições objetivas e subjetivas são expressas nos assentamentos rurais, que reúnem alguns dos setores sociais mais empobrecidos da população. Quando olhados em conjunto, tanto as posições anteriores ao assentamento quanto a posição social de agricultor-assentado não definem apenas condições restringidas de geração de renda e trajetórias sociais marcadas pela instabilidade das condições de vida, mas também condicionam uma determinada economia psicossocial a essas parcelas subordinadas da população.

\section{Bibliografia citada}

ALENTEJANO, Paulo Roberto Raposo. Reforma agrária, território e desenvolvimento no Rio de Janeiro. 2003. Tese (Doutorado)-CPDA/UFRRJ, Rio de Janeiro, 2003.

BATISTA, Elicardo Heber Almeira et al. Reflexões sobre pluriatividade: os casos do assentamento de Zumbi dos Palmares - Campos Goytacazes/RJ e da comunidade rural Santana de Minas - São Francisco (MG). In: ENCONTRO DA REDE DE ESTUDOS RURAIS, 3, Campina Grande, 2008. CD-ROM.

BAVARESCO, Pedro Antônio. Assentamentos Annoni fase IV [RS]: uma análise de seu desempenho sócio-econômico. Dissertação (Mestrado)-CPDA/UFRRJ, Rio de Janeiro, 1998. 
BENETTI, Maria D. Reestruturação do agronegócio no Brasil e no Rio Grande do Sul nos anos 90: concentração, centralização e desnacionalização do capital. In: FLIGENSPAN, Flávio Benevett (Coord.). Economia gaúcha e reestruturação nos anos 90. Porto Alegre: FEE, 2000. p. 63-117.

BergamasCO, S. M. P. P.; NORDER, Luiz Antonio Cabello. A alternativa dos assentamentos rurais: organização social, trabalho e política. 1. ed. São Paulo: Terceira Margem, 2003. v. 1, 191p.

; Assentamentos e assentados no Estado de São Paulo: dos primeiros debates as atuais reflexões. Reforma Agrária, v. 33, p. 203-226, 2006.

BOURDIEU, Pierre. A ilusão biográfica. In: AMADO, Janaína; FERREIRA, Marieta de Morais. Usos \& abusos da história oral. Rio de Janeiro: FGV, 1996. p. 183-191.

CASTRO, Elisa Guaraná de. Sonhos, desejos e a "realidade": herança, educação e trabalho de 'jovens rurais' da Baixada Fluminense/RJ. 2004. Disponível em: www.nead.org.br (artigo do mês). Acesso em: 12 maio 2005.

CARNEIRO, Maria José. Ruralidade: novas identidades em construção. Estudos Sociedade e Agricultura, Rio de Janeiro, n. 11, p. 53-75, 1998.

FAO/PNUD - MAARA. Principais indicadores dos assentamentos de reforma agrária. Projeto BRA/87/022, Brasília, dez., 2002.

FERNANDES, Bernardo Mançano. MST. Formação e territorialização. São Paulo: Hucitec, 1996.

FERRANTE, Vera Lúcia; BARONE, Luís Antônio. O lugar dos assentamentos rurais no desenvolvimento local/regional: dilemas e perspectivas futuras. Revista Uniara, Araraquara, SP, n. 17/18, p. 155-180, 2006.

FONTE, Maria. Tradiciones y nuevos modelos de ruralidad em las regiones del mediterráneo. Estudos Sociedade e Agricultura, Rio de Janeiro, n. 15, p. 147-157, 2000.

FOUCAULT, Michel. Nascimento da Biopolítica: curso dado no Collège de France (1978-1979). São Paulo: Martins Fontes, 2008.

GAIGER, Luiz Inácio. A práxis coletiva dos sem-terra: rumo à unidade ou à heterogeneidade cultural? Cadernos de Sociologia: Produção Familiar, Processos e Conflitos Agrários, Porto Alegre, v. 6, p. 177-203, 1994.

- As condições socioculturais do engajamento no MST. Estudos Sociedade e Agricultura, Rio de Janeiro, n. 13, p. 70-92, out. 1999.

. Entre as razões de crer e a crença na razão: mobilização coletiva e mudança cultural no campesinato meridional. Revista Brasileira de Ciências Sociais, Rio de Janeiro, Ano 10, n. 27, fev. 1995.

GARCIA JR., Afrânio. Geração de rendas, sua distribuição e trajetórias diferenciais em assentamentos de reforma agrária no Brasil (1985-1989): comentários sobre o estudo da 
FAO. In: ROMEIRO, A. et al. (Org.). Reforma agrária: produção, emprego e renda - o relatório da FAO em debate. Rio de Janeiro: Vozes; IBASE/FAO, 1994. p. 87-98.

GARCIA JR., Afrânio. Terra de trabalho. Rio de Janeiro: Paz e Terra, 1983.

GONÇALVES, Renata. "Vamos Acampar?" A luta pela terra e a busca pelo assentamento de novas relações de gênero no MST do Pontal do Paranapanema. 2005. Tese (Doutorado em Ciências Sociais)- IFCH/Unicamp, Campinas, 2005.

GUBERT, José Eduardo; BASSO, Nilvo. Fortalecimento de agricultores familiares no noroeste do Estado do Rio Grande do Sul. ADSA: análise diagnóstico de sistemas agrários: Jóia e Eugênio de Castro. Ijuí: Fidene/DEAg/Unijuí, 2005.

GUANZIROLI, Carlos et al. Agricultura Familiar e Reforma Agrária no Século XXI. Rio de Janeiro: Garamond, 2001.

INCRA - Instituto Nacional de Colonização e Reforma Agrária. Relatório. Porto Alegre, 2008.

LEITE, Sérgio Pereira et al. Impacto dos assentamentos: um estudo sobre o meio rural brasileiro. Brasília: IICA/NEAD; São Paulo: Ed. Unesp, 2004.

LEITE, Sérgio Pereira. Orçamentos familiares e estratégias socioeconômicas em assentamentos rurais. Estudos Sociedade e Agricultura. Rio de Janeiro, n. 21, p. 118-151, out. 2003,

LOERA, Nashieli Cecilia Rangel. A busca do território: uma aproximação à diversidade do seu significado entre os sem-terra. 2004. Dissertação (Mestrado em Antropologia Social)-IFCH/Unicamp, Campinas, 2004.

MARX, Karl. O capital. Tradução Regis Barbosa e Flávio R. Kothe. São Paulo: Abril Cultural, 1983. Tomo I.

MARTINS, José de Souza. O Cativeiro da terra. São Paulo: Livraria Editora Ciências Humanas, 1979.

MEDEIROS, Leonilde Servolo et al. (Org.). Assentamentos rurais: uma visão multidisciplinar. São Paulo: USP, 1994.

MEDEIROS, Rosa Maria Vieira; SOSA JUNIOR, Denir de Oliveira. Desterritorialização e (Re) territorialização dos trabalhadores rurais sem-terra na Campanha Gaúcha. In: ENCONTRO DA REDE DE ESTUDOS RURAIS, 1, Niterói, 2006.

MOREIRA, Roberto José. Cultura, política e o mundo rural contemporâneo. Estudos Sociedade e Agricultura, Rio de Janeiro, v. 20, p. 90-118, 2003.

. Renda da natureza e territorialização do capital. In: . Terra, poder e território. São Paulo: Expressão Popular, 2007. p. 27-56.

- Agricultura familiar e assentamentos rurais: competitividade, tecnologia e integração social. In: . Agricultura familiar: processos sociais e competitividade. Rio de Janeiro: Mauad, 1999a. p. 157-180. 
MOREIRA, Roberto José. A pequena produção e a composição orgânica do capital. In: Agricultura familiar: processos sociais e competitividade. Rio de Janeiro:

Mauad, 1999b. p. 101-117.

Reflexões sobre o campesinato e a economia política. In:

Agricultura familiar: processos sociais e competitividade. Rio de Janeiro: Mauad, 1999c. p. 85-100.

- Agricultura familiar e sustentabilidade: valorização e desvalorização econômica e cultural das técnicas. In:___ Agricultura familiar: processos sociais e competitividade. Rio de Janeiro: Mauad, 1999d. p. 181-198.

NEVES, Delma Pessanha. Assentamento rural: confluência de formas de inserção social. Estudos Sociedade e Agricultura. Rio de Janeiro, n. 13, p. 5-28, out. 1999.

NORDER, Luiz Antonio Cabello. Mercantilização da agricultura e desenvolvimento territorial. In: SCHNEIDER, Sérgio (Org.). A diversidade da agricultura familiar. Porto Alegre: UFRGS, 2006. p. 57-81.

PICCIN, Marcos Botton. Habitus e agricultores assentados: um estudo de caso a partir do assentamento Ceres, RS. Rio de Janeiro: Edur, 2011 (no prelo).

et al. Análise do processo de constituição e desestruturação da Cooperativa de Agricultores Assentados Terra Vida - Coopervida, RS. Revista NERA. Presidente Prudente, São Paulo, Ano 12, n. 4, p. 72-96, 2009.

- Lógicas socioculturais e estratégias produtivas no assentamento menina dos olhos dos sem-terra. 2007. Dissertação (Mestrado)-CPDA/UFRRJ, Rio de Janeiro, 2007.

; MOREIRA, Roberto José. A agroecologia nas trajetórias sociais de agricultores-assentados na granja "menina dos olhos dos sem-terra": o caso do Assentamento Ceres, RS. Estudos Sociedade e Agricultura. Rio de Janeiro, v. 14, n. 2, p. 254-311, out. 2006.

PLOEG, Jan Douwe van der. O modo de produção camponês revisitado. In: SCHNEIDER, Sérgio (Org.). A diversidade da agricultura familiar. Porto Alegre: UFRGS, 2006. p. 1354 .

ROCHE, Jean. A colonização alemã e o Rio Grande do Sul. Porto Alegre: Globo, 1969.

SCHNEIDER, Sérgio (Org.). A diversidade da agricultura familiar. Porto Alegre: UFRGS, 2006.

. A pluriatividade na agricultura familiar. Porto Alegre: UFRGS, 2003.

SILVA NETO, Benedito; BASSO, David (Org). Sistemas agrários do Rio Grande do Sul: análise e recomendações de políticas. Ijuí: Unijuí, 2005.

SIGAUD, Lygia. A forma acampamento: notas a partir da versão pernambucana. Novos Estudos, São Paulo, n. 58, p. 73-92, 2000. 
SILVA, José Graziano da (Org). Questão agrária, industrialização e crise urbana no Brasil: Ignácio Rangel. Porto Alegre: UFRGS, 2000.

SPAROVEK, Gerd (Coord.). Análise territorial da produção nos assentamentos. Brasília: MDA; NEAD, 2005.

WANDERLEY, Maria de Nazareth Baudel. A emergência de uma nova ruralidade nas sociedades modernas avançadas - o "rural" como espaço singular e coletivo. Estudos Sociedade e Agricultura, n. 15, p. 87-145, out. 2000.

. O camponês: um trabalhador para o capital. Campinas: Unicamp, 1979.

WOORTMANN, Klaas. "Com parente não se neguceia": o campesinato como ordem moral. Anuário Antropológico, Brasília, n. 87, p. 11-76, 1990.

ZARTH, Paulo Afonso. Colonização e ocupação do espaço agrário do Rio Grande do Sul. Ciência \& Ambiente, Santa Maria, n. 33, p. 155-164, jul./dez. 2006.

\section{Entrevistas citadas}

Sr. Pedro. Entrevista concedida em 2006.

Sr. Francisco. Entrevista concedida em 2006. 